scents the room in which the patient is; the second is its high price. The latter, however, would soon be reduced, if any considerable demand arose for it.

\section{A SUCCESSFUL CASE OF SPLENOTOMY.*}

\section{BY Dr. A. MARTIN, BERLIN.}

THE great progress of modern laparotomy, which we all agree we owe principally to the energetic initiative of our English brethren, is sufficiently proved to encourage us to-day to proceed to the removal of growths. and degenerate abdominal organs which but a short time ago seemed to be a noli me tangere. The benefit of this we gynæcologists particularly enjoy, as only thereby the removal of those genital organs which seem to be singularly exposed to degeneration has become common property amongst us. Looking at the results of ovariotomy, we can boldly proceed to the removal, if it become necessary, of any other abdominal organ, provided only that this step do not injure irreparably the bodily system. And here only begins the great difficulty, namely, to know what organs the body can lose without fatal result. Experiments on animals cannot be accepted as the best evidence in the settlement of this question; much more do we owe to those accidents which destroy or wholly arrest the function of the organs of the abdominal cavity. If this can be proved in a convincing manner, the removal of degenerate organs or parts of them can be a question only of improved surgical manipulation.

An organ, the function of which has remained a problem to physiologists, the spleen, seems to have been always protected against surgical interference because of its unknown value in the corporeal system. But there are partial and even entire interruptions of the function of this organ, chiefly from traumatic causes, which show that we can easily spare it from the body; and, as far as I have examined the literature of the subject, these accidental cases encourage us to make a favourable prognosis when surgical interference becomes necessary. And bold surgeons have taught us already that this extirpation can be done. The results ot these cases have not, indeed, until now been very favourable to this extirpation, as out of nine patients only three recovered from the operation. But if we examine the causes of the six failures, we find that one died of pyæmia ; two sank under the influence of shock; while the remaining three died of bleeding, one upon the operation-table, and the two others a few hours after the operation. The three survivors recovered rapidly, and, as far as it is stated, enjoyed good health, suffering from no disturbance of digestion or other sources. It is much to be regretted that observations were not made on them as to changes in the blood. At all events, it seems to be ascertained that we can live without the function of the spleen.

Concerning the operation itself, in all these cases the organ has been considerably enlarged; by such enlargement, the spleen always grows towards the median abdominal line, and in no instance was there any difficulty noted in finding the diseased organ or in removing it through the abdominal incision. Surely, the difficulties of the operation are all accumulated in the ligation of the splenic vessels, which must be cut in the most dangerous neighbourhood of the stomach or of the pancreatic glands. In both cases, it is evident that the ligatures are likely. to slip, or to injure to a fatal degree the functions of these organs. If, then, besides these dangers, the vessels are enormously distended with blood during the operation, we need not suppose that these splenic arteries and veins are particularly fragile if the ligatures cut through when tightened and come away. Nor should we be much surprised if the ligatures should slip, as we cannot put them far enough from the ends of the divided vessels; and just in these parts that would seem very necessary, as the blood from the great aorta runs directly into them with enormous force. Billroth is particularly afraid, it seems, of injuring the pancreatic gland, and concludes from his case, in which the ligature slipped off the artery two hours after the operation, that, in spite of the dangers resulting therefrom, we ought to tie the ligature even around a part of the pancreas, in order to secure the arteries and veins. Péan has fixed the ligature like a pedicle in the wound; others have taken the whole of the vessels in one; while others have secured the vessels singly. I think we should act every one according to his own experience, and that the method of treatment in every instance has to accommodate itself to particular circumstances. As far as these differ, the probability of the result differs. This evidently is proved by my own case, in which splenotomy was greatly facilitated by the single circumstance that the organ had left its usual place and was wander-

* Read in the Section of Surgery at the Annual Meeting of the British Medical Association in Manchester, August 1877 . ing about in the whole abdominal cavity, being suspended only by a pedicle which contained the elongated splenic vessels.

The patient, a poor hunchback woman, thirty-one years of age, menstruated abundantly at eleven. At the age of twenty-one, she suffered for a short time with rheumatism, and since then with palpitation of the heart. She has been twice confined : first in $187 \mathrm{I}$, when forceps were used; secondly in 1875, spontaneously, though her pelvis was narrowed in consequence of early rickets. In her last childbed, which I had to witness in the Royal Maternity of Berlin, she suffered from lochiometra, in consequence of anteflexion of the puerperal uterus, which began the ninth day after confinement. Soon after her dismissal, she returned to the hospital to obtain relief from intense pain in the groin, which began as soon as she undertook the duties of her previous occupation, that of a laundress. By-and-by, the symptoms of endocarditis became intensely marked, and at the same time a wandering spleen was diagnosed. This wandering spleen at that time did not inconvenience the patient at all, as there was no soreness or tenderness, and she willingly appeared at the clinics of the different schools of Berlin. Notwithstanding the great attention paid to her in these clinics, her general health did not improve; especially, since her last confinement, chronic metritis and prolapsus of the anterior vaginal wall had developed to a high degree. Although she was treated in nearly all the clinical offices in the city, she became worse, and in time was hardly able to walk about. From the beginning of the year 1876 , she felt other pains than those of the prolapsus and of the metritis, and attributnd them to the wandering spleen. At last, she resorted also to galvanism, which for some time diminished the pains; but, during last winter, she obtained but little relief from it, and could obtain no rest from her pains until she had taken enormous doses of morphia. She also came to my ambulance, complaining less of her menorrhagia and the prolapsus than of the severe pains in the spleen, which she diagnosed perfectly well herself. Repeated microscopical investigations proved the constitution of the blood and the number of the red corpuscles and their relation to the white ones to be quite normal, at least as far as could be ascertained by comparing the specimens with the blood of healthy persons. The corpuscles themselves were absolutely healthy. There could be no doubt as to the nature of the wandering tumour in the abdominal cavity. It was strikingly evident, as well from the volume as from the form, that the tumour felt immediately behind the very thin abdominal walls was the spleen. The hilus could be easily recognised, so also the borders of the tumour, which could not be mistaken; while the whole organ seemed not to be enlarged. Under percussion, the normal place of the spleen was empty immediately after the patient had been walking ; but, after some hours' rest in bed, the dulness in this region returned. After she had walked to and fro for some time, and after pressing over the abdominal wall, the top of the spleen came down to the pelvic brim, so that it could be touched per vaginam. Without difficulty, it could be pressed down in the pelvis alongside of the uterus.

As the pain, which was constant and intense, and which continued even when the patient herself seemed unconscious from chloroform, could not be diminished by drugs or any other means, I thought I was justified in delivering the poor woman of the organ, especially since it was probably in a state of degeneration, though I was not, through the changes, able to satisfy myself as to this question. The operation of extirpation seemed the more justifiable, since I knew, through the successful cases of the other authors, that the removal would not necessarily endanger the system. I therefore proposed the operation of splenotomy to a council of medical friends, and, as they endorsed the step, I proposed it to the patient herself, adding at once a statement of the dangers of the operation. In despair, she agreed at once to undergo it, and I had some difficulty to convince her that we must wait until after the next menstrual period.

On May 13th, 1877, I performed the operation of splenotomy, observing most accurately the antiseptic method of operating. Before the patient was placed on the table, the spleen was pressed into the median line. This being done, chloroform was given. The incision, which was in the median line, was about four inches in length, extending from the umbilicus downwards. The walls of the abdomen were extremely thin. Under the peritoneal opening, the omentum presented, but the spleen had disappeared; after some difficulty, it was found in its normal place. I was astonished to find how difficult it was to bring the organ out of this position and through the incision. The hilus was occupied by a group of vessels, which seemed to be quite separated from each other and to run free of all connections with neighbouring organs a distance of about four inches. The group next the lower - surface of the organ contained one large artery. This I tied as firmly as possible with a silk ligature. Then I took the middle group, containing some arteries and the splenic vein, 
which was about the size of a thick goose quill. The ligature was carried around it in the same manner as in the case of the other vessels. While ligaturing the third group, the silk broke, wounding a small artery. In a moment, a hæmatoma was formed by the blood effused into the peritoneal layer around the vessels. I now tied the vessel further from the spleen, and stopped all bleeding completely. I next cut through the vessels and took away the spleen. Although the bleeding had ceased, I surrounded the vessels with a thick silk ligature, and fastened the whole once more. After this, there was no bleeding whatever. After sleaning off the effused blood, I dropped the pedicle, which had commenced to swell most fearfully, back into the cavity. This being quite clean, I closed the abdominal walls and covered the wound with antiseptic dressing. Twenty-eight minutes after the operation was commenced, the patient awoke in her bed feeling quite comfortable.

The removed organ was only a little larger and heavier than normal; it was densely covered with star-like old and recent superficial cicatrices of perisplenic inflammation. The parenchyma itself was not changed, nor was the blood the vessels contained patholugically changed.

The patient recovered without any febrile reaction. Being accustomed to the use of morphia, she received, during the first three days, several doses per diem. For the first day, she took only small pieces of ice. On the second day, the bowels began to act spontaneously; then she had beef-tea and wine. On the fifth day, she felt so well that, during the momentary absence of the nurse, she left her bed to look out of the window. On the fourth day, the bandages were changed under carbolic spray, the wound having healed almost completely per primam intentionem. On the ninth day, she felt so well that $I$ could not detain her in bed any longer, and on the eleventh day I found her sitting in the sunlight at the door of my clinic. The patient felt extremely well ; the old pains, which I believe to be caused as well by the chronic inflammation as by the tension of the peritoneum by the organ, had disappeared, nor were any functions of the body disturbed. In different preparations, I examined her blood microscopically, and sometimes in these examinations I was favoured with the kind assistance of Dr. Gravitz, of Virchow's Pathological Institution; but we found no alteration of the corpuscles, either in form or behaviour, nor in their relative number, nor was the fluid changed from its state previous to the operation. During the third week, the patient suffered serious indigestion from improper food. The menses were postponed six weeks, as has frequently occurred before; and the flow was not so profuse as during the former periods. I was the more satisfied by the rapid recovery of the patient, for there thrombi were surely to be expected to form in the long splenic arteries, and I feared serious trouble therefrom. Nevertheless, no symptoms of any danger could be discovered, and three weeks after the operation the patient returned to her work, and at every opportunity hastened to show herself to those who had previously treated her.

This, gentlemen, is the case I have to report to you. It proves un. doubtedly that we can exist without the spleen-that splenotomy does not change the constitution of the blood. Besides this, the case proves that, as soon as the tying of the vessels is facilitated, the operation of splenotomy will not be such a dangerous measure as it has been thought to be, and especially when it is done under the antiseptic regimen, which in Germany at this time would not be omitted in this operation.

\section{CASE OF OSTEO-SARCOMA OF TIBIA, RECURRING IN STUMP OF THIGH, AND PROBABLY} AFFECTING THE LUNG.

BY JOHN EWENS, L.R.C.P., L.R.C.S.Ed., Surgeon to the Hospital for Sick Children, Bristol.

The BRITISH Medical JourNal of December 29th, 1877, contains a report of osteo-sarcoma of the fethur, with death from subsequent deposit in the lung, read before the annual meeting of the Association in August last, by Mr. Heath of Manchester. As the following case seems to be in some respects somerhat antagonistic to the conclusions arrived at by Mr. Heath, in connection with the opinion of the late Sir W. Fergusson, it will not, I think, be without some practical interest.

A boy, aged 8 , was admitted into the Hospital for Sick Children, Bristol, in May i 876 , with a large tumour of the upper extremity of the left tibia. The history given was that, some weeks before, he had been struck by a stone flung by another boy, and that he had walked some distance in the snow, and got chilled. The very rapid growth and general appearance of the tumour led to the diagnosis of malignant disease, and that nothing but prompt amputation far beyond the limits of disease could afford the least chance of saving life. The inguinal glands, though more distinct than usual on account of the extreme emaciation, did not appear to be diseased. There was no abdominal tenderness, or evidence of any visceral disease. Amputation was performed by the circular method about the middle of the thigh. The wound was dressed with carbolised oil, and the arteries tied with car. bolised catgut. Rapid union of the deep structures occurred by first intention, and the patient was discharged quite well in about a month. The whole of the upper third of the tibia was involved in the malignant growth, which also extended into the joint (but did not invade the femur) and for a considerable distance down the cancellous tissue of the bone. The soft parts were also extensively involved. Unfortunately, the hospital cards containing detailed notes as to circumference of the tumour, etc., have been lost or mislaid.

On October $14^{\text {th }}$, the boy returned with a tumour, of the size of a small orange, on the inner and anterior side of the stump, which, he said, had been growing about six weeks. It was not very painful, and was somewhat movable, and probably had deep attachments. He said it had commenced on the surface. The inguinal glands were not tender or materially enlarged. His general health was wretched; hurriet respiration; quick pulse; leading me to suspect extensive disease of the lung. On examination, dulness with extensive crepitation over the whole of the posterior aspect of the chest was detected. The only question remaining was the propriety of removal of the stump at the hip-joint, but this was negatived after further careful examination of the amputated limb (which is now preserved in the museum of our medical school), the femur being found free from disease; and the in ference was that, as the whole of the diseased structures had been removed, the malignant cachexia was so decided as not only to reproduce the disease in the stump, but most probably the lung-affection was of a cancerous nature. He was therefore discharged, and lived about a month. I visited him about a week before his death, and found that the tumour had rapidly increased in size and appeared as though it would soon ulcerate; but this did not occur, and the chest-disease was the immediate cause of death. As he lived ten miles from Bristol, no post mortem examination could be obtained.

It appears to me that this case proves an exception to the rule laid down by Sir W. Fergusson, referred to by Mr. Heath, "that large malignant growths, springing from the long bones, do not, after amputation, if the whole of the diseased stractures be removed, return in the stump, but at some distant part ; and, therefore, it is not necessary to amputate above the knee in case of the tibia, or at the hip-joint in case of the femur".

Now, in the case I record, it is obvious that the disease did return in the stump-whether prior or subsequently to the lung-disease I cannot say-and that it progressed with a rapidity which would have speedily of itself proved fatal ; and yet it was my own opinion, and that of my colleagues, that I operated far beyond the limits of disease then apparent. Hence it would seem to be impossible, with certainty, to promise immunity from a return of this formidable disease, whilst in suitable cases we must not hesitate to amputate.

Mr. Holmes (Surgical Treatment of Children's Diseases) in the course of his observations on this subject, says (second edition, page 334) "Usually, however, the case proceeds very differently; the malignant deposit reappears in the course of a few weeks after removal of the limb, either in the glands or in the interior of the body."

Mr. Erichsen (Science and Art of Surgery, seventh edition, vol. II, page 207), in connection with this subject, says: "I believe that return is much more speedy and certain after amputation, in the peripheral than in the central form of malignant disease of bone, provided that in the latter the whole of the bone has been removed; this is due to the more extensive corntamination of the soft parts in the former than in the latter case." Again, "If the limb be removed in the continuity of the diseased bone, there must necessarily be a great probability of a very rapid retarn of the morbid action in the stump; and this probability amounts to a certainty in those cases in which the disease is central, and in which the whole of the medullary canal and cancellous structure are implicated and infiltrated with cancer. In cases of peripheral disease, this teturn in the same bone may not take place"; but, as there can be little certainty about the matter before operation, he advises removal at or above the next joint. Further on, he observes: "In some forms of trialignant bone-disease, however, the muscles inserted into the affected bone often become speedily contaminated, and this contamination may spread widely through the substance or along the sheath of any particular muscle. Hence, I think the rule in these cases should be to amputate not only above the diseased bone, but, if practicable, above the origins of the muscles in the neighbourhood of the disease." 